\title{
Medical waste management in clinical and educational laboratories affiliated to Rafsanjan University of Medical Sciences, Iran, in 2015
}

\author{
Mohseni Moghadam F, MD ${ }^{1}$, Tashakori M, $\mathrm{PhD}^{2}$, Shahidi Zandi B, $\mathrm{MD}^{3}$, Hadavi M, MSc ${ }^{4^{*}}$, \\ Akbarpoor V, MSc ${ }^{5}$, Kazemi F, BSc ${ }^{6}$, Moosavi M, $\mathrm{MSc}^{5}$ \\ 1-Facully Member, Dept. of Basic Science, Paramedical Faculty, Rafsanjan University of Medical Sciences, Rafsanjan , \\ Iran. 2- Assistant Prof., Dept. of Basic Science, Paramedical Faculty ,Rafsanjan University of Medical Sciences, Rafsanjan, \\ Iran. 3- MD in Medical Laboratory Basic Science, Rafsanjan University of Medical Sciences, Rafsanjan, Iran. 4- PhD \\ Student, Dept. of Anesthesiology, Paramedical Faculty, Rafsanjan University of Medical Sciences, Rafsanjan, Iran. 5- MSc \\ in Microbiology, Dept. of Basic Science, Paramedical Faculty, Rafsanjan University of Medical Sciences, Rafsanjan, Iran. \\ 6- BSc in Laboratory Sciences, Dept. of Basic Science, Paramedical Faculty, Rafsanjan University of Medical Sciences, \\ Rafsanjan, Iran.
}

\begin{abstract}
Received: October 2016, Accepted: January 2017

Background: Laboratory wastes are one of the environmental issues of developing countries and cause diseases and epidemics. Laboratory waste management is planned with the aim of preventing unfavorable effects on human health and the environment. The aim of the present study was to determine the status of medical waste management in clinical laboratories affiliated with Rafsanjan University of Medical Sciences, Iran, in 2015.

Materials and Methods: The present study was conducted through a census in all clinical laboratories of Rafsanjan University of Medical Sciences. Data were collected using a checklist that was designed and confirmed by the Iranian Health and Treatment Ministry. After administrative coordination, the checklist was completed through visits and interviews. The collected data were analyzed using descriptive tests in SPSS software.

Results: The results showed that, in $40 \%$ of cases, individuals responsible for the collection of waste had received the necessary training. In addition, in $28.6 \%$ of cases, containers were labeled in order to determine the type of waste inside the container. In $57.1 \%$ of laboratories, there was no list of chemicals which must not be mixed during waste collection. The waste was disinfected using an autoclave in only $14.3 \%$ of cases.

Conclusions: In the present study, the waste classification operation of the majority of laboratories was incomplete. In order to reduce contamination in these centers, measures must be taken regarding the disposal of waste at the site of its production. Furthermore, individuals responsible for collection and transference of waste must comply with personal protection measures.
\end{abstract}

Keywords: Infectious Waste, Waste Management, Laboratory, Medical Waste, Iran.

\section{Introduction}

In recent years, medical waste has gained importance in terms of the environment and public health and has become a challenge for the authorities. According to the waste management law of Iran, all infectious and hazardous waste generated by hospitals, health care institutions, health care centers, and medical diagnostic laboratories are identified as medical waste (1). The waste generated by hospitals and health care centers include solid waste produced during health care and treatment processes, vaccination, and researchrelated procedures in laboratories or similar centers (2). These wastes constituted 1-2 percent of solid urban waste and are classified as hazardous wastes, and thus, are of grave

* Corresponding author: Maryam Hadavi, Dept. of Anesthesiology, Paramedical Faculty, Rafsanjan University of Medical Sciences, Rafsanjan, Iran.

E-mail: hadavimaryam@yahoo.com 
importance in terms of health (3). Therefore, lack of control and disregard for correct management of hospital waste, such as collection method, and sanitary transportation and disposal, can result in the outbreak of diseases and urban and rural epidemics which in addition to being a threat to public health and the environment, results in high expenses $(4,5)$. In other words, infectious wastes are substances that can cause infectious diseases. Based on this definition, all hazardous waste containing viruses and other pathogens are recognized as infectious waste. Biological wastes include tissues, organs, amputated limbs, pus and blood stained cotton, and bodily fluids such as urine and feces. These substances are highly hazardous and infectious and must be collected and disposed according to specific regulations and standards (5).

A national legal framework, internal management systems, programs aimed at training personnel and ensuring their safety, and programs to estimate the amount of waste produced and assess and determine effective and suitable disposal techniques in every country are necessary for the improvement of hospital waste management (6). The importance of this issue is such that, in many developed countries, specific laws and regulations have been established and imposed for the authorities of medical institutes. These regulations not only apply to institutes, but also private physician offices (7). The hospital and laboratory waste collection and disposal system of 5 hospitals in Italy, Spain, France, England, and Germany were evaluated in 2000 (8). For example, in Freiburg University Hospital, Germany, 54 laws (36 laws at the national level, 5 at the regional level, and 13 at the hospital level) exist for the correct management of hospital waste. In a study in 14 health centers in Libya and a study in Brazil, the lack of categorization of wastes at the production and temporary storage location was reported as undesirable $(9,10)$. Nevertheless, a study reported satisfactory waste management in Bahrain and a more satisfactory condition in this regard in governmental centers compared to private centers (11).

Today, the increase in the rate and variety of waste and its resulting environmental pollution and hazards is considered as one of the issues of human societies. Due to the importance of infectious and biological waste in the transmission of diseases and damage to the environment, the present study was conducted to assess the management and disposal of infectious and biological waste in clinical laboratories affiliated with Rafsanjan University of Medical Sciences, Iran, in 2015.

\section{Materials and Methods}

In this descriptive and cross-sectional study, all clinical laboratories affiliated with Rafsanjan University of Medical Sciences were assessed through a census in 2015. Of the 7 laboratories, 3 were within schools and 4 were educational laboratories. The laboratories were assessed in terms of the categorization, collection, storage, and transportation of waste, and etcetera. Data were collected through observational method and using a 23item checklist. After administrative coordination, the checklist was completed through visits and interviews by lecturers of the Department of Laboratory Sciences. The items of the standard checklist of the Iranian Health and Treatment Ministry were used for the development and designing of the checklist (12). The collected data were analyzed using descriptive tests (frequency and percentage) in SPSS software (version 18, SPSS Inc., Chicago, IL, USA).

\section{Results}

In the present study, 7 clinical laboratory centers affiliated to Rafsanjan University of Medical Sciences were evaluated. The characteristics of the studied laboratories in terms of type of waste produced and type of services provided are presented in table 1 . 
Table 1: The characteristics of the studied laboratories in terms of type of waste produced and type of services provided

\begin{tabular}{|c|c|c|}
\hline Laboratory name & Type of services provided & Type of waste produced \\
\hline Ali-ibn Abi Talib Hospital & $\begin{array}{l}\text { Clinical diagnosis-training of } \\
\text { students }\end{array}$ & Infectious, sharp, and bilogical \\
\hline Enghelab & $\begin{array}{l}\text { Clinical diagnosis-training of } \\
\text { students }\end{array}$ & Infectious, sharp, and bilogical \\
\hline Pathobiology & $\begin{array}{l}\text { Clinical diagnosis-training of } \\
\text { students }\end{array}$ & Infectious, sharp, and bilogical \\
\hline Health Center & $\begin{array}{l}\text { Clinical diagnosis-training of } \\
\text { students }\end{array}$ & Infectious, and sharp \\
\hline $\begin{array}{l}\text { Microbiology Center of the } \\
\text { School of Medicine }\end{array}$ & Training of students & Infectious, and sharp \\
\hline $\begin{array}{l}\text { Hematology Center of the School } \\
\text { of Allied Medicine }\end{array}$ & Training of students & Infectious, sharp, and biological \\
\hline $\begin{array}{l}\text { Biochemistry Center of the } \\
\text { School of Medicine }\end{array}$ & Training of students & $\begin{array}{l}\text { Chemical, infectious, sharp, and } \\
\text { biological }\end{array}$ \\
\hline
\end{tabular}

The results showed that, in $28.6 \%$ of the cases, the possibility of leakage of leachate from waste bags existed. The waste was first sterilized using an autoclave, and then, collected in $14.3 \%$ of cases. In $16.7 \%$ of laboratories, waste was stored inside the laboratory for a short period of time (1 day). In addition, $50 \%$ of laboratories had a specific room for waste storage. In $50 \%$ of cases, waste was piled up in the courtyard until it was collected by municipal waste disposal vehicles.

In $85.7 \%$ of cases, waste was stored in sealed containers and the size of the containers was in accordance with the volume and type of waste stored; however, in only $28.6 \%$ of cases, these containers had labels to specify the type of waste stored. In $100 \%$ of cases, waste collection bags and containers were replaced immediately after waste collection. Different color bags and containers were used for differentiation of different types of waste (e.g., infectious and normal waste) in $42.9 \%$ of cases. Moreover, $28.6 \%$ of laboratories had a list of chemical substances used in some educational laboratories that must not be mixed during collection due to their reaction with each other. Safety boxes were used for the collection of syringes and other sharp objects in all studied laboratories.

In all studied laboratories, the personnel who transferred the waste lacked protective clothing and footwear. Only $40 \%$ of these individuals had received training regarding the principles of hygiene and $28.6 \%$ had thick and resistant gloves (Table 2).

Table 2: The status of infectious and biological waste disposal in clinical and educational laboratories of Rafsanjan University of Medical Sciences, Iran

\begin{tabular}{cllll}
\hline \multirow{2}{*}{ Row } & \multicolumn{1}{c}{ Question } & \multicolumn{2}{c}{ Items } \\
\cline { 3 - 4 } $\mathbf{1}$ & $\begin{array}{l}\text { Is the leakage of leachate possible from the containers in which waste is } \\
\text { collected (e.g., waste bags)? }\end{array}$ & No & Unclear \\
\hline $\mathbf{2}$ & Can the containers in which waste is collected be washed out and reuse? & 71.4 \\
\hline $\mathbf{3}$ & Is laboratory waste stored in sealed containers? & 28.6 & 57.1 & 14.3 \\
\hline $\mathbf{4}$ & Is the waste storage location close to the waste production location? & 71.4 & 28.6 \\
\hline $\mathbf{5}$ & Do the waste containers have sufficient resistance against sharp objects? & 85.7 & 14.3 \\
\hline $\mathbf{6}$ & Are the waste containers suitable for the type and volume of the waste stored? & 85.7 & 14.3 \\
\hline $\mathbf{7}$ & Are the waste containers labeled to determine the type of waste stored? & 28.6 & 71.4 \\
\hline $\mathbf{8}$ & $\begin{array}{l}\text { Do the personnel who collect the waste in the laboratory know the correct way } \\
\text { of using the equipment and instruments? }\end{array}$ & 28.6 & 71.4 \\
\hline $\mathbf{9}$ & $\begin{array}{l}\text { Do the personnel who transfer waste containers have thick and resistant } \\
\text { gloves? }\end{array}$ & 28.6 & 71.4 \\
\hline
\end{tabular}




\begin{tabular}{|c|c|c|c|c|}
\hline 10 & $\begin{array}{l}\text { Do the personnel who transfer waste containers have protective footwear in } \\
\text { case of the collapsing of containers onto their feet? }\end{array}$ & 0 & 100 & \\
\hline 11 & $\begin{array}{l}\text { Are the waste bags and containers replaced immediately after waste } \\
\text { collection? }\end{array}$ & 100 & 0 & \\
\hline 12 & $\begin{array}{l}\text { Are measures taken in the laboratory to ensure the lack of toxicity and danger } \\
\text { of the waste? }\end{array}$ & 14.3 & 85.7 & \\
\hline 13 & $\begin{array}{l}\text { Have the personnel who collect waste received the necessary training on the } \\
\text { principles of hygiene and safety? }\end{array}$ & 40 & 60 & \\
\hline 14 & Is the waste stored inside the laboratory? & 16.7 & 83.3 & \\
\hline 15 & $\begin{array}{l}\text { Is the waste stored in a specific room inside the laboratory separated from } \\
\text { laboratory equipment? }\end{array}$ & 50 & 33.3 & 16.7 \\
\hline 16 & $\begin{array}{l}\text { Does the laboratory have a room with a cold storage container for the } \\
\text { temporary storage of waste? }\end{array}$ & 0 & 100 & \\
\hline 17 & Are waste containers sealed when they are three-quarters full? & 85.7 & 14.3 & \\
\hline 18 & Does the waste storage room have an impermeable floor? & 57.1 & 28.6 & 14.3 \\
\hline 19 & $\begin{array}{l}\text { Is a certain individual responsible for transferring the waste from the } \\
\text { laboratory? }\end{array}$ & 83.3 & 16.7 & \\
\hline 20 & $\begin{array}{l}\text { Is the list of chemicals which should not be mixed during collection (those } \\
\text { which react with each other) considered in the classification of laboratory } \\
\text { waste? }\end{array}$ & 28.6 & 57.1 & 14.3 \\
\hline 21 & $\begin{array}{l}\text { Are syringes and other sharp objects separated and collected in special } \\
\text { containers? }\end{array}$ & 100 & 0 & \\
\hline 22 & $\begin{array}{l}\text { Are infectious, dangerous, and general waste separated and classified using } \\
\text { different color bags and containers? }\end{array}$ & 42.9 & 57.1 & \\
\hline 23 & Are expired chemical substances disposed with other wastes? & 42.9 & 57.1 & \\
\hline
\end{tabular}

\section{Discussion}

The necessity of strict management of laboratory and hospital waste around the world is felt more and more each day (7). The present study was performed with the aim of the evaluation of medical waste management in clinical and educational laboratories affiliated to Rafsanjan University of Medical Sciences in 2015. The results suggested that hospital and clinical laboratories within schools of Rafsanjan University of Medical Sciences were similar in terms of the status of infectious and biological waste disposal and no significant differences were observed among them in terms of the studied items. This finding was not in agreement with that of the study conducted in Tabriz University of Medical Sciences, Iran (2). This may be due to the shared personnel and officials of these laboratories, the proximity of their location, and limitation in the number of laboratories in the present study.

In the present study, very few of the personnel responsible for waste collection had received training on waste collection methods. This finding is in accordance with that of the studies performed in Tabriz University of Medical Sciences (2) and Tehran University of Medical Sciences (13). This finding shows the necessity of addressing this issue and providing educational programs for these employees.

In terms of laboratory waste classification, only $28.6 \%$ of laboratories had a satisfactory performance. In $14.3 \%$ of cases, laboratory waste classification status was unclear. In a study conducted in Gorgan, Iran, the researchers found that, in order to decrease the volume of infectious and hazardous waste, the correct separation and classification of waste must be conducted at the site of its production (14). The classification of laboratory waste will decrease the possibility of contamination of environments outside the hospital, contamination of water and soil, and damage to those responsible for the disposal of this waste.

In $42.9 \%$ of the studied cases, different colored bags and containers were used for the classification of different types of waste (e.g., infectious and normal waste) which was not 
satisfactory. The results of the present study are in agreement with that of the study by Arab $\mathrm{M}$ and his colleagues, who reported an unsatisfactory status in educational hospital wards in this regard (15). Moreover, a study on infectious hospital waste management in Egypt showed lack of attention to waste disposal, especially in terms of waste classification (16). Nevertheless, a study conducted in health centers in Korea showed that waste classification was performed within the majority of health centers, and then, the waste was transported by vehicles to a temporary storage site (17). Furthermore, incinerators and autoclaves were used for the disinfection and disposal of waste and the final product was buried outside the centers (17). Reduced production, classification, and recycling of waste in the three categories of quasi-household, infectious, and recyclable waste has been introduced in health centers in Istanbul, Turkey, as one of the best and most cost-effective clinical waste management methods, especially for developing countries, and has been implemented in all hospitals in Turkey (18).

In the present study, syringes and other sharp objects were collected in safety boxes in all laboratories. This finding was satisfactory and in agreement with that of the study by Shahriary A and his colleagues (14). This finding signifies the recognition of the importance of the disposal method of this type of waste and its role in the prevention of damage to individuals responsible for waste disposal and infectious disease transmission.

The limitation of the present study was the small number of studied samples. It is suggested that a broader study be conducted in different hospital wards, clinics, and Social Security Organization and private laboratories of the city in order to assess the status of hospital waste management and the issues present in each of its stages (classification, collection, temporary storage, and transference).

\section{Conclusion}

The present study results suggested that the waste classification operation of most laboratories was incomplete. In order to reduce contamination in these centers, measures must be taken regarding the disposal of waste at the site of its production. Due to the importance of infectious and biological waste in disease transmission and environmental damage, the supervision and control of authorities over the collection and disposal of this type of waste in hospital and university laboratories must be increased. Since equipment that can reduce waste hazard, such as autoclave, are present in all laboratories, the use of this equipment for the reduction of hazard and prevention of disease transmission must be made obligatory and the collection of waste must be controlled regularly.

\section{Acknowledgements}

The authors wish to thank the authorities of the laboratories of Rafsanjan University of Medical Sciences and the lecturers of the Department of Laboratory Sciences for their cooperation and assistance in this study.

Conflict of interest: None declared.

\section{References}

1. Department of Environment. Human environment. Low of Waste management. Tehran: Department of Environment; 2004. Available from: http://www.doe.ir/Portal/file/?121335/8modiriyate-pasmandha.pdf

2. Taghipour H. Mosaferi M. Chracterization of medical waste from hospitals in Tabriz, Iran. Sci Total Environ 2009; 407(5):1527-35.

3. Omrani GhA, Atabi F, Sadeghi M, BanaeiGhahfarokhi B. Comparison of technical, hygienic and economic aspects of three methods of Disposal of hospital waste Contains Sterilization, Incineration and landfill of hygienic in Shahrekord. Journal of Environmental Sciences and Technology 2007; 9(2):37-45.

4. Chaerul M, Tanaka M, Shekdar AV. A system dynamics approach for hospital waste management. Waste Manag 2008; 28(2):442-9. 
5. Dehghani MH, Fazelinia F, Omrani GhA, Nabizadeh R, Azam K. Investigation of management statuson medical wastes in public hospitals of Arak city. Iranian Journal of Health and Environment 2011; 4(1):93-104.

6. Moazzam A, Kuroiwa Ch. Status and challenges of hospital solid waste management: case studies from Thailand, Pakistan, and Mongolia. Journal of Material Cycles and Waste Management 2009; 11(3):251-7.

7. Department of Environmental Conservation (DEC). Division of Materials Management. Guidance for regulated medical wastes treatment, storage, containment, transport and disposal. New York State: Department of Environmental Conservation (DEC); 1999. Available from: http://www.dec.ny.gov/regulations/8752.html

8. Daschner F. Reduction and utilization of hospital waste, with the focus on toxic and infectious waste. EU-Project No.: LIFE 96 ENV/D/10. Freiburg, Switzerland; European Union: 2000.

9. Sawalem M, Selic E, Herbell JD. Hospital waste management in Libya: a case study. Waste Manag 2009; 29(4):1370-5.

10. Blenkham JL. Medical waste management in south of Brazil. Waste Manag 2006; 26(3):3157.

11. Mohamed LF, Ebrahim SA, Al-Thukair AA. Hazardous healthcare waste management in the
Kingdom of Bahrain. Waste Manag 2009; 29(8):2404-9.

12. Ministry of Health and Medical Education. Environment \& Occupational Health Center. Criteria and methods executive management of medical wastes and related waste. Tehran: Ministry of Health and Medical Education; 2008.

13. Dehghani MH, Azam K, Changani FA, Dehghnifard E. Quanity and quality of medical wastes in hospitals of Tehran University Medical Sciences in year 2006. Hakim Health Systems Research Journal 2008; 11(1):40-7.

14. Shahryari A, Nooshin S, Borghei PS. Medical waste management in Gorgan hospital. Journal of Health 2011; 2(1):49-55.

15. Arab M, Ravangard R, Omrani Gh, Mahmodi M. Wastes management assessment at publicteaching and private hospitals affiliated to Teheran University of Medical Sciences, Iran. Journal of Health Administration 2010; 12(38):71-7.

16. Mohamed Soliman S, Ibrahim Ahmed A. Overview of biomedical waste management in selected Governorates in Egypt: a pilot study. Waste Manag 2007; 27(12):1920-3.

17. Jang YC, Lee C, Yoon OS, Kim H. Medical waste management in Korea. J Environ Manage 2006; 80(2):107-15.

18. Birpinar ME, Bilgili MS, Erdogan T. Medical waste management in Turkey: A case study of Istanbul. Waste Manage 2009; 29(1):445-8. 